\title{
The Chemical Composition of Lambda in Paramecium aurelia, Stock 299
}

\author{
By W. J. van WAGTENDONK AND R. B. TANGUAY \\ Veterans Administration Hospital and the Department of Biochemistry, University \\ of Miami Medical School, Coral Gables 34, Florida, U.S.A.
}

(Received 25 February 1963)

\begin{abstract}
SUMMARY
Paramecium aurelia containing $\lambda$ particles was grown in an axenic medium; the $\lambda$ particles were purified by passing homogenized organisms through a column of the anion exchange resin ECTEOLA. The $\lambda$ particles were stained heavily with pyronin $Y$ and weakly with the Feulgen procedure, in vivo and in vitro. Chemical analysis of the $\lambda$ particles revealed that a single particle contained: 0.026 picogram (pg.) DNA, 0.230 pg. RNA, $4 \cdot 0$ pg. protein, $0 \cdot 350$ pg. carbohydrate, $5 \cdot 6$ pg. phospholipid. The RNA/ DNA ratio in the $\lambda$ particle was 8.8 as compared with a RNA/DNA ratio of 11.3 in the $\kappa$ particle. Both particles contain about the same amount $\left(0.0049 \mathrm{pg}\right.$., and $0.0045 \mathrm{pg} . / \mu^{3}$, respectively) of DNA, yet the $\lambda$ particles stained very faintly with the Feulgen procedure, while the $\kappa$ particles stained very heavily.
\end{abstract}

\section{INTRODUCTION}

Several stocks of Paramecium aurelia have been shown to possess certain cytoplasmic inclusions named $\kappa, \pi, \mu$ and $\lambda$. The longest known and most widely studied particle $\kappa$ (Sonneborn, 1959) is a Feulgen-positive rod-shaped body, randomly scattered throughout the cytoplasm; its presence confers protection against, and results in the liberation of, a toxic agent. Particle $\pi$ is a mutant form of $\kappa$; its presence neither confers protection against, nor results in, the liberation of a toxic substance. Beale \& Jurand (1960) published a study of the $\mu$ particle, which occurs in syngen $\mathbf{1}$, stock 540. This stock is a mate-killer, having the same properties as the mate-killers earlier described by Siegel (1953). The presence of a cytoplasmic particle, $\lambda$, in stock 299 of syngen 8 , was discovered by Schneller (1958); the $\lambda$-containing killer organisms cause sensitive organisms of stock 139 to lyse within 20 min. Ever since the discovery of $\kappa$ particles there have been discussions about their nature. The features used for distinguishing endogenous genetic particles from intracellular symbionts have proved to be indecisive criteria. As part of an investigation to try to establish the phylogenetic relations of the various cytoplasmic particles, the determination of the chemical constitution of the $\lambda$ particle was undertaken, in order to compare it with the previously determined composition of $\kappa$ (Smith \& van Wagtendonk, 1962). The advent of an axenic medium for the culture of particle-bearing paramecia (Soldo, 1961) made it possible to determine the chemical constitution of these particles without the danger of contamination by bacterial constituents. 


\section{METHODS}

An axenic culture of Paramecium aurelia stock 299, syngen 8, containing $\lambda$ particles was obtained from Dr A. T. Soldo (Biological Research Division, Schering Corporation, Bloomfield, New Jersey). The organisms were maintained at $27^{\circ}$ in the axenic medium described by Soldo (1961). This medium consists of a mixture of salts, water-soluble vitamins, stigmasterol, proteose peptone, Edamine S (Sheffield Chemicals, Norwich, New York) and a non-dialysable fraction of a heated yeast extract (Miller \& van Wagtendonk, 1956). Subcultures were made every 5 days by inoculating $3.0 \mathrm{ml}$. fresh medium with $0.1-0.5 \mathrm{ml}$. from a previous old culture. Large cultures of paramecia were grown in $500 \mathrm{ml}$. Soldo medium contained in 2.51 . Erlenmeyer flasks. The population density of these cultures after 5 days ranged from 7000 to 10,000 organisms $/ \mathrm{ml}$. The paramecia were periodically checked for the presence of $\lambda$ particles by staining with aceto-orcine. Fixed preparations were stained by the methyl green-pyronin $\mathrm{Y}$ technique of Kurnick (1953) or by the Feulgen procedure as modified by Rafalco (1946). The time of hydrolysis in the latter procedure is critical and should not exceed $5 \mathrm{~min}$; ; otherwise negative results are obtained.

Removal of ribonucleic acid from the $\lambda$ particles was accomplished by treating the organisms for $30 \mathrm{~min}$. at $37^{\circ}$ with $1 \%$ (w/v) solution of crystalline ribonuclease in water (previously heated for $10 \mathrm{~min}$. at $90^{\circ}$ to inactivate any contaminating deoxyribonuclease).

Large quantities of pure particles were obtained by a method modified from the one used by Smith (1962). Cultures (3-4 1.) of $\lambda$-bearing paramecia were centrifuged at $3000 \mathrm{~g}$ for $10 \mathrm{~min}$; the supernatant fraction was then subjected to centrifugation at $15,000 \mathrm{~g}$ for $20 \mathrm{~min}$. to sediment $\lambda$ particles which might have been liberated from ruptured organisms. This sediment was added to the first sediment, and the combined fractions suspended in $15 \mathrm{ml}$. sterile saline solution $(0 \cdot 9 \%, w / v)$. The above centrifugation procedure was repeated twice. The final sediment was suspended in $10 \mathrm{ml} .0 .1 \mathrm{M}$-phosphate buffer (pH 6.9). A homogenate was prepared by using the syringe technique (Sonneborn, 1950) and the homogenate was passed through an ECTEOLA (epichlorohydrin triethanolamine-cellulose) column, $2 \mathrm{~cm}$. in diameter and $1 \mathrm{~cm}$. high, prepared $20 \mathrm{~min}$. before use by suspending in $1.5 \mathrm{~g}$. ECTEOLA in $50 \mathrm{ml}$. phosphate buffer. The effluent was passed several times through a freshly prepared column until the particles appeared clean when viewed under brightly illuminated phase-contrast.

The clean particles were separated from the phosphate buffer by centrifugation $(25,000 \mathrm{~g}$. $)$ and suspended in isotonic salt solution for the determination of the total number present (by counting a measured sample) and for the cytochemical and chemical analyses. The procedure outlined by Paul (1958) was used for the determination of the major constituents of the $\lambda$ particles. The amount of lipid present was obtained by a modification of Bloor's colorimetric procedure (1947). Organic phosphorus was determined on a measured sample of the ethanol +ether soluble fraction by the method of Griswold, Humoller \& McIntyre (1951); this value multiplied by 25 gives the amount of phospholipid present (Lees, 1957). Carbohydrate was measured according to the procedure of Trevelyan \& Harrison (1952). Total nucleic acid was estimated by determining the absorption at $260 \mathrm{~m} \mu$ of measured 
Table 1. Chemical composition of $\lambda$ particles

\begin{tabular}{|c|c|c|c|c|c|c|c|c|c|c|c|c|c|c|c|c|c|}
\hline \multirow{3}{*}{$\begin{array}{c}\text { Expt. } \\
\text { no. }\end{array}$} & \multirow{3}{*}{$\begin{array}{c}\text { Total } \\
\text { no. of } \\
\text { particles }\end{array}$} & \multicolumn{2}{|c|}{ Lipid } & \multicolumn{2}{|c|}{$\begin{array}{c}\text { Lipid } \\
\text { phosphorus }\end{array}$} & \multicolumn{2}{|c|}{ Phospholipid } & \multicolumn{2}{|c|}{ Carbohydrate } & \multicolumn{2}{|c|}{ Nucleic acids } & \multicolumn{2}{|c|}{ DNA } & \multicolumn{2}{|c|}{ RNA } & \multicolumn{2}{|c|}{ Protein } \\
\hline & & $\mathbf{T}^{*}$ & $P^{*}$ & $\mathbf{T}$ & $\mathbf{P}$ & $\mathbf{T}$ & $\mathbf{P}$ & $\mathbf{T}$ & $\mathbf{P}$ & $\mathbf{T}$ & $\mathbf{P}$ & $\mathbf{T}$ & $\mathbf{P}$ & $\mathbf{T}$ & $\mathbf{P}$ & $\mathbf{T}$ & $\mathbf{P}$ \\
\hline & & $\mu \mathrm{g}$. & pg. & $\mu \mathrm{g}$. & pg. & $\mu \mathrm{g}$ & pg. & $\mu \mathrm{g}$ & pg. & $\mu \mathrm{g}$. & pg. & $\mu \mathrm{g}$. & pg. & $\mu \mathrm{g}$. & pg. & $\mu \mathrm{g}$. & pg. \\
\hline 1 & $7.5 \times 10^{7}$ & - & - & - & - & 一 & - & 27 & $0 \cdot 36$ & 16 & $0 \cdot 21$ & $1 \cdot 1$ & 0.013 & $14 \cdot 9$ & $0 \cdot 197$ & - & - \\
\hline 2 & $8.8 \times 10^{7}$ & 422 & $4 \cdot 8$ & - & - & - & - & 23 & $0 \cdot 26$ & 20 & $0 \cdot 23$ & $\mathbf{3} \cdot \mathbf{0}$ & $0 \cdot 034$ & $17 \cdot 0$ & $0 \cdot 193$ & - & - \\
\hline 3 & $1.7 \times 10^{8}$ & 660 & $4 \cdot 0$ & - & 一 & - & - & 60 & $0 \cdot 36$ & 48 & $0 \cdot 29$ & $8 \cdot 2$ & $0 \cdot 048$ & $39 \cdot 8$ & $0 \cdot 240$ & 940 & $5 \cdot 56$ \\
\hline 4 & $1.5 \times 10^{8}$ & - & - & - & - & - & - & 67 & $0 \cdot 44$ & 32 & $0 \cdot 21$ & $\mathbf{2} \cdot \mathbf{0}$ & $0 \cdot 013$ & $30 \cdot 0$ & $0 \cdot 197$ & - & - \\
\hline 5 & $1.5 \times 10^{8}$ & 1727 & $8 \cdot 22$ & - & - & - & - & 70 & $0 \cdot 33$ & 40 & $0 \cdot 19$ & $2 \cdot 6$ & 0.012 & $37 \cdot 4$ & $0 \cdot 178$ & 1000 & $4 \cdot 76$ \\
\hline 6 & $1 \cdot 6 \times 10^{8}$ & 819 & $5 \cdot 12$ & $31 \cdot 5$ & $0 \cdot 20$ & 788 & $4 \cdot 80$ & 54 & $0 \cdot 34$ & 48 & $0 \cdot 30$ & $4 \cdot 4$ & $0 \cdot 028$ & $43 \cdot 6$ & $0 \cdot 272$ & 650 & $4 \cdot 06$ \\
\hline 7 & $1.2 \times 10^{8}$ & 517 & $4 \cdot 31$ & $22 \cdot 0$ & $0 \cdot 18$ & 550 & 4.58 & 39 & 0.33 & 36 & $0 \cdot 30$ & $4 \cdot 0$ & 0.033 & $32 \cdot 0$ & 0.266 & 359 & $3 \cdot 00$ \\
\hline 8 & $1.1 \times 10^{8}$ & 630 & $5 \cdot 73$ & $27 \cdot 0$ & $0 \cdot 24$ & 675 & $6 \cdot 13$ & 41 & $0 \cdot 37$ & 34 & $0 \cdot 31$ & $3 \cdot 7$ & $0 \cdot 033$ & $30 \cdot 3$ & $0 \cdot 276$ & 364 & $\mathbf{3} \cdot \mathbf{3 0}$ \\
\hline 9 & $1 \cdot 3 \times 10^{8}$ & 945 & $7 \cdot 26$ & $36 \cdot 8$ & $0 \cdot 28$ & 920 & $7 \cdot 07$ & 52 & $0 \cdot 40$ & 38 & $0 \cdot 29$ & $\mathbf{3} \cdot \mathbf{0}$ & 0.023 & $35 \cdot 0$ & $0 \cdot 270$ & 418 & $3 \cdot 22$ \\
\hline Average & - & - & $5 \cdot 64$ & - & $0 \cdot 23$ & - & $5 \cdot 64$ & - & $0 \cdot 35$ & - & $0 \cdot 26$ & - & 0.026 & - & $0 \cdot 23$ & - & $3 \cdot 98$ \\
\hline
\end{tabular}

0
3
3
0
0
0
$x$
$x$
0
0 
samples of the perchloric acid fraction by a Beckman D.U. spectrophotometer. The method of Ceriotti (1955) was used to determine deoxyribonucleic acid and ribonucleic acid. The residue of the fractionation procedure was digested with the acid mixture of Brüel, Holter, Linderstrøm-Lang \& Rozits (1947) and the amount of ammonia formed measured with Nessler reagent; the obtained value was multiplied by $6 \cdot 25$ to give the amount of protein present.

\section{RESULTS}

Cytochemical observations. Large numbers of rod-shaped particles, randomly distributed throughout the cytoplasm, were visualized when organisms of the killer stock 299 were stained with aceto-orcein (Pl. 1, fig. 1). These particles also stained deeply with pyronin $\mathrm{Y}$ (Pl. 1, fig. 2), indicating the presence of large amounts of ribonucleic acid. After treatment with ribonuclease no pyronin $Y$ positiveparticles were observed (Pl. 1, fig. 3). Results obtained with the Feulgen procedure were much less pronounced. A careful study of Pl. 1, fig. 4, shows that there were small Feulgen-positive rods scattered throughout the cytoplasm. The random distribution and the shape of these bodies suggest that the Feulgen-positive material was most probably associated with the $\lambda$ particles. Particles obtained by the purification procedure and placed directly on slides stained positive with the pyronin $\mathrm{Y}+$ methyl green mixture.

Chemical determinations. The results of nine chemical analyses of purified $\lambda$ particles are shown in Table 1 . The particles are characterized by a relatively large content of protein and lipid. Most of the lipid was present as phospholipid, whose specific type is not known. The concentration of protein and lipid tended to fluctuate, possibly with the rate of reproduction of the particles. The amount of carbohydrate was low. The average content of deoxyribonucleic acid and ribonucleic acid/single particle was $0 \cdot 026$ and $0 \cdot 23 \mathrm{pg}$., respectively.

\section{DISCUSSION}

The most interesting results obtained in this work are those concerning the deoxyribonucleic acid (DNA) and ribonucleic acid (RNA) content of the $\lambda$ particle. A comparison of the cytochemical and chemical data on the constitution of the two killer particles $\kappa$ and $\mu$, with the data obtained for the $\lambda$ particle, reveals that all three rod-shaped particles contain DNA. In the particles $\kappa$ and $\mu$, the DNA was first cytochemically demonstrated; from these results two conclusions were reached: (a) DNA is distributed uniformly throughout the $\kappa$ particle; $(b)$ the $\kappa$ particle contains 'massive amounts of DNA' (Sonneborn, 1959). From cytochemical tests the composition of the $\lambda$ particle appears to be fundamentally different, since the Feulgen stain indicates that DNA is present in very small amounts. The chemical analysis of the $\kappa$ and $\lambda$ particles revealed however that $\kappa$ contains less DNA and more RNA per unit volume than does the $\lambda$ particle.

Various explanations for the discrepancy between the cytochemical observations and the chemical data can be suggested: $(a)$ the $\lambda$ DNA is more resistant to acid treatment, like the chloroplast DNA described by Chiba \& Sugahara (1957); $(b)$ the $\lambda$ DNA may be dispersed through the particle very dilutely; $(c)$ the $\lambda$ DNA may be in a precursor state, not stainable by the Feulgen procedure (Vendrely, 1955). The 
first explanation is not acceptable because it was found in the present work that the $\lambda$ DNA was very labile under acid treatment. It does not seem very likely that DNA would be uniformly distributed in the $\lambda$ particle and therefore more dilute than in the $\kappa$ particle. On the contrary, a careful examination of $\mathrm{Pl}$. 1, fig. 4, shows that the $\lambda$ DNA appears to be concentrated at one end of the particle. Chayen (1959) remarked that the drastic conditions of the Feulgen test might disrupt the cell organization and cause a re-location of the DNA or even a diffusion of cytoplasmic DNA into the nucleus. The uniform distribution of DNA throughout the $\kappa$ particle may be a result of similar events and this might lead to an erroneous interpretation

Table 2. Comparison of $D N A$ and $R N A$ concentration in $\kappa$ and $\lambda$ particles

\begin{tabular}{lll} 
& $\kappa$ particle & \multicolumn{1}{c}{$\lambda$ particle } \\
Size (approximately) & $2 \cdot 25 \times 1 \cdot 0 \mu$ & $6 \cdot 75 \times 1 \cdot 0 \mu^{*}$ \\
DNA/unit volume $\left(\mu^{3}\right)$ & $0 \cdot 0045 \mathrm{pg}$. & $0 \cdot 0049 \mathrm{pg}$. \\
RNA/unit volume $\left(\mu^{3}\right)$ & $0 \cdot 058 \mathrm{pg}$. & $0.043 \mathrm{pg}$. \\
RNA/DNA ratio & $11 \cdot 3$ & $\mathbf{8 \cdot 8}$ \\
\multicolumn{2}{c}{$*$ Sonneborn, Mueller \& Schneller (1959). }
\end{tabular}

of the cytochemical observations. The lability of $\lambda$ DNA under acid treatment might have prevented the re-location of the DNA throughout the particle. The available evidence does not rule out the possibility that the lambda DNA is present in a precursor form. It seems clear from the present work and that by Smith \& van Wagtendonk (1962) that the determination of the chemical composition of these cytoplasmic particles can at best furnish an ambiguous criterion for the biological status of these particles. Not until it can be shown that these cytoplasmic particles have a metabolism of their own, either independent of, or co-ordinated with, that of the host will it be possible to classify these particles as viruses, parasites (Sonneborn, 1961) or as endogenous components of the cell.

This work was supported by grants from the U.S. National Institutes of Health (NIH E 3644- $\mathrm{C}_{1}-\mathrm{C}_{2}$ ) and the National Science Foundation (NSF G 14569). One of us (R.B.T.) held a National Defense Act Fellowship. This report is based on a thesis submitted by R. B. Tanguay in partial fulfilment of the requirements for the degree of Master of Science in the Graduate School of the University of Miami, Coral Gables, Florida, U.S.A.

\section{REFERENCES}

Beale, G. H. \& Jurand, A. (1960). Structure of the mate-killer $(\mu)$ particle in Paramecium aurelia, stock 540. J. gen. Microbiol. 23, 43.

BLoor, W. R. (1947). A colorimetric procedure for the determination of small amounts of fatty acid. J. biol. Chem. 170, 61.

Brüel, D., Holter, H., Linderstrøm-Lang, D. \& Rozits, K. (1947). A micromethod for the determination of total nitrogen (accuracy 0.005 $\mu \mathrm{g}$. N). Biochim. biophys. acta, 1, 101.

Ceriotti, G. (1955). Determination of nucleic acids in animal tissues. J. biol. Chem. 214, 59 .

Chayen, J. (1959). The quantitative cytochemistry of DNA and its significance in cell physiology and heredity. Exp. Cell Res. (Suppl.), 6, 115.

Chiba, Y.S. \& Sugahara, K. (1957). The nucleic acid content of chloroplasts isolated from spinach and tobacco leaves. Arch. Biochem. 71, 367. 
Griswold, B. L., Humoller, F. L. \& McIntyre, A. R. (1951). Colorimetric procedure for the determination of phosphorus. Analyt. Chem. 23, 192.

Kunnick, N. B. (1953). Pyronin-Y in the methyl green-pyronin histological stain. Stain Tech. 30, 213.

LEES, M. B. (1957). Preparation and analysis of phosphatides. Meth. Enzymol. 3, 330.

Mrller, C. A. \& van Wagtendonk, W. J. (1956). The essential metabolites of a strain of Paramecium aurelia (stock $47 \cdot 8$ ) and a comparison of the growth rate of different strains of Paramecium aurelia in axenic culture. J. gen. Microbiol. 15, 280.

PaUl, J. (1958). Determination of the major constituents of small amounts of tissue. Analyst, 83, 87.

RAfalco, J. S. (1946). A modified Feulgen technique for small and diffuse chromatin elements. Stain Tech. 21, 91.

Schneller, M. V. (1958). A new type of killing action in a stock of Paramecium aurelia from Panama. Proc. Ind. Acad. Sci. 67, 302.

Siegel, R. W. (1953). A genetic analysis of the mate-killer trait in Paramecium aurelia, variety 8 . Genetics, 38,550 .

Sмiтн, J. E. (1962). Purification and chemical characterization of Kappa of stock 51, syngen 4, Paramecium aurelia. Ph.D. thesis: Indiana University.

Smith, J. E. \& van Wagtendonk, W. J. (1962). Chemical identification of kappa. Fed. Proc. 21, 153.

Soldo, A. T. (1961). Cultivation of two strains of killer Paramecium aurelia in axenic medium. Proc. Soc. exp. Biol., N.Y. 65, 278.

Sonneborn, T. M. (1950). Methods in the general biology and genetics of Paramecium aurelia. J. exp. Zool. 113, 87.

Sonnebonn, T. M. (1959). Kappa and related particles in Paramecium aurelia. Advanc. Virus Res. 6, 229.

Sonnebons, T. M. (1961). Kappa particles and their bearing on host-parasite relations. Perspectives in Virology, 3, 5. Ed. by M. Polard. Minneapolis: Burgess Publishing Comp.

Sonneborn, T. M., Mueller, J. A. \& Schneller, M. V. (1959). The classes of kappa-like particles in Paramecium aurelia. Anat. Rec, 134, 642.

Trevelyan, W. E. \& Harrison, J. S. (1952). Studies on yeast metabolism. 1. Fractionation and microdetermination of cell carbohydrates. Biochem. J. 50, 298.

Vendrely, R. (1955). The deoxyribonucleic acid content of the nucleus. The Nucleic Acids, 2, 155. Ed. by E. Chargaff and J. N. Davidson. New York: Academic Press.

\section{EXPLANATION OF PLATE}

Fig. 1. Paramecium aurelia, stock 299. The rod-shaped particles found throughout the cytoplasm and overlying the deeply stained macronucleus are the $\lambda$ particles. Strained with Aceto-orcein. Magnification, $\times 1000$ on film.

Fig. 2. Paramecium aurelia, stock 299. The rod-shaped particles in the cytoplasm deeply stained with Methyl green-pyronin Y mixture represent the $\lambda$ particles. Magnification $\times 500$ on film.

Fig. 3. Paramecium aurelia, stock 299 treated with $1 \%$ RNA-ase solution for $30 \mathrm{~min}$. at $37^{\circ}$ and subsequently stained with Methyl green-pyronin Y mixture. No $\lambda$ particles can be seen. Magnification, $\times 500$ on film.

Fig. 4. Paramecium aurelia, stock 299, stained with the Feulgen procedure. Note the small dots of Feulgen-positive material throughout the cytoplasm. Magnification, $\times 500$ on film. 

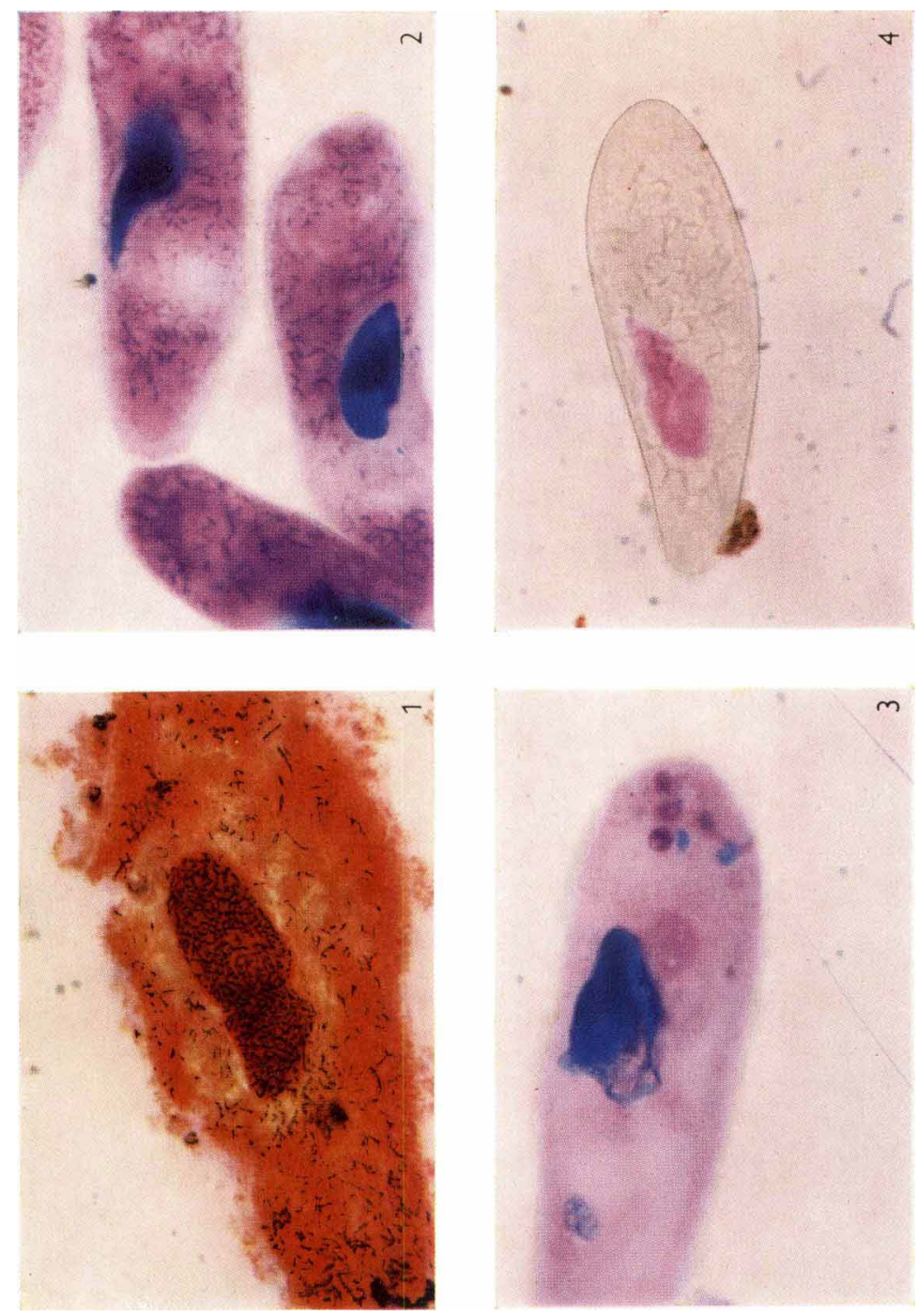